\title{
INVENTÁRIO TURÍSTICO: CONSTATAÇÕES E CONSIDERAÇÕES
}

\author{
Tourist Inventory: findings and considerations \\ Inventário Turístico: constataciones y consideraciones \\ Claudia Corrêa de Almeida Moraes \\ Universidade Federal Fluminense (UFF),, Brasil \\ claudiamoraes@uol.com.br \\ Isabela Fátima Fogaça \\ Universidade Federal Rural do Rio de Janeiro (UFRRJ), \\ Brasil \\ isafog@hotmail.com \\ Carlos Alberto Lidizia Soares \\ Universidade Federal Fluminense (UFF), Brasil \\ csoares@id.uff.br
}

DOI: https://doi.org/10.18472/cvt.20n1.2020.1749 Redalyc: http://www.redalyc.org/articulo.oa? id $=115462634006$

Recepción: 07 Agosto 2019

Aprobación: 20 Febrero 2020

\section{Resumo:}

Entre 2015 e 2017, no Estado do Rio de Janeiro, foi desenvolvido por duas instituições públicas, a Secretaria de Turismo do Estado do Rio de Janeiro (SETUR RJ) e a Universidade Federal Fluminense (UFF), um projeto de Inventariação da Oferta Turística (IOT-RJ) em 23 municípios que participavam do Programa Regional de Desenvolvimento do Turismo do Rio de Janeiro (PRODETUR RJ). O projeto apontou para alguns aspectos positivos e para fragilidades que levaram a reflexão sobre as vantagens $\mathrm{e}$ limitações das metodologias empregadas, os sucessos e percalços na organização da pesquisa e a alimentação e divulgação dos dados. Apesar dos avanços tecnológico e dos resultados positivos obtidos, a experiência apontou para limitações, especialmente quanto a logística, ao uso da tecnologia, a disposição dos dados finais, a divulgação e a compreensão por parte dos usuários dos inventários, de seu valor no processo decisório de planejamento do turismo e necessidade de atualização constante.

PALAVRAS-CHAVE: Inventário da oferta turística, PRODETUR, IOT-RJ, Rio de Janeiro.

\section{Abstract:}

Between 2015 and 2017, in the State of Rio de Janeiro, two public institutions, the Secretaria de Turismo do Estado do Rio de Janeiro (SETUR RJ) and the Universidade Federal Fluminense (UFF), developed a Program of Inventory of Tourism Offering (IOT- RJ) in 23 municipalities that participated in the Tourism Development Project (PRODETUR RJ). The project pointed to some positive aspects and fragilities that led to reflection on the advantages and limitations of the methodologies used, successes and mishaps in the research organization, feeding, and dissemination of data. Despite technological advances and positive results, experience has shown numerous limitations, especially in terms of logistics, the use of technology, the provision of the final data, the dissemination and the understanding by users of inventories of their value in the decision-making process tourism planning and the need for constant updating.

KEYWORDS: Tourist offer inventory, PRODETUR, IOT-RJ, Rio de Janeiro.

\section{RESUMEN:}

Entre 2015 y 2017, en el Estado de Rio de Janeiro, fue desarrolhado por dos instituciones públicas, la Secretaría de Turismo del Estado de Río de Janeiro (SETUR RJ) y la Universidad Federal Fluminense (UFF), un proyecto de Inventario de la Oferta Turistica (IOT-RJ) en 23 municipios que participaban en el Programa Regional del Desarollo del Turísmo de Río de Janeiro (PRODETUR RJ). El proyecto señalo algunos aspectos positivos y debilidades que llevaron a la reflexión sobre las ventajas y limitaciones de las metodologías empleadas, los éxitos y percances en la organización de la investigación y la alimentación y divulgación de los datos. A pesar de los avances tecnológicos y los resultados positivos obtenidos, la experiencia apuntó limitaciones, especialmente en cuanto a la logística, el uso de la tecnología, la disposición de los datos finales, la divulgación y comprensión por parte de los usuarios de los inventarios de su valor en el proceso decisorio de planificación turística y necesidad de actualización constante. 
PaLABras CLAVE: Inventario de la oferta turística, PRODETUR, IOT-RJ, Rio de Janeiro.

\section{INTRODUÇÃo}

A informação está entre os conteúdos mais importantes para a gestão e organização do fenômeno turístico. Para Biz, Nakatani \& Pavan (2013), ela é resultado de dados levantados, organizados e processados por intermédio de ação humana, de acordo com propósitos e significados para a sua existência e aplicação. Quando um conjunto de componentes inter-relacionados com vistas a coletar (ou recuperar), processar, armazenar e distribuir informações é criado para o suporte de tomada de decisão, coordenação e controle de um processo é denominado sistema de informações, segundo Laudon \& Laudon (2002). Entre os sistemas de informações, existem os que tratam das informações turísticas (STIs) cunhados para apoiar o fenômeno turístico.

Costa, Rita \& Água (2001) apresentam no quadro 1, exemplos de informação necessárias aos diferentes agentes/elementos que compõem o sistema turístico.

\section{OUADRO 1 \\ Informações Turísticas}

\begin{tabular}{|c|c|}
\hline Demanda/Turistas & $\begin{array}{l}\text { In formaçâo sobre destinos turisticos, atrativos, } \\
\text { equipamentos e serviços, facilidades, disponibilidades, } \\
\text { preços, informação geográfica, histórica e climática, } \\
\text { entre outros. }\end{array}$ \\
\hline Oferta/Destinos & $\begin{array}{l}\text { In formaçâo sobre a trativos, equipamentos e serviços, } \\
\text { cadeia produtiva, turistas, in termediários } e \\
\text { concorrentes, entre outros }\end{array}$ \\
\hline Intermediários & $\begin{array}{l}\text { In formação sobre tendências no mercado turistico, } \\
\text { destinos turisticos, facilidades, disponibilidades, preços, } \\
\text { pacotes turisticos e concorrentes, entre outros }\end{array}$ \\
\hline $\begin{array}{l}\text { Organizações de } \\
\text { Marketing de Destinos } \\
\text { Turísticos }\end{array}$ & $\begin{array}{l}\text { Informação sobre tendências no sector, dimensão e } \\
\text { natureza dos fluxos turisticos, políticas e planos de } \\
\text { desenvolvimento, entre outros. }\end{array}$ \\
\hline
\end{tabular}

Fonte: Adaptada de Costa, Rita \& Água, 2001.

Observando estes exemplos, percebe-se que para o planejamento e gestão do turismo há a necessidade de informações sobre a oferta turística, visto que o turista é o agente que move o turismo e sua mobilidade se dá por causa da oferta.

Desde a segunda metade do século XX, no âmbito da gestão do Turismo no Brasil, o desenvolvimento de SITs vem sendo um desafio enfrentado pelos órgãos de turismo do país (seja em nível federal, estadual ou municipal). Existe tecnologia necessária para subsidiar a construção e o desenvolvimento de SITs, mas por questões de gestão, poucos projetos obtêm resultados. A primeira experiência em desenvolver um SIT nacional ocorreu com a criação do Ministério do Turismo (MTur) e do Plano Nacional de Turismo (PNT) 2003-2007, o Projeto do Inventário da Oferta Turística - INVTur. Este projeto tinha a pretensão de inventariar a oferta turística de grande parte dos municípios do país (Brasil, 2006).

Estudos concernentes ao INVTur demonstram que o projeto apresenta problemas quanto ao conteúdo e a forma indicada de estruturação da pesquisa, além da sua descontinuidade. Esta insatisfação pode ser observada em algumas publicações como Moesh \& Pinto (2006), Pinto (2007), Almeida (2009), Almeida \& Moura (2009), Moura, Gondim, Pinheiro \& Simões (2009), Perantoni, Silva \& Nagabe (2013). Assim, nesse intervalo de tempo houve algumas adaptações nesta metodologia, no entanto, sua base continuou seguindo a mesma linha. 
Recentemente, entre 2015 a 2017, desenvolveu-se um projeto de Inventariação da Oferta Turística nos Destinos Turísticos do Estado do Rio de Janeiro (IOT-RJ), baseado nos princípios adotados pelo INVTur (Rio de Janeiro, 2016). Durante sua execução, despertou-se, também, para muitas indagações sobre a metodologia empregada, e, até mesmo, sobre o real valor do inventário para os municípios (personificados em seus gestores) e para o Estado. Questionamentos, ao nosso entender, pertinentes, na medida em que se desenvolvem em todos os estados da federação inventários turísticos usando esta orientação, e poucas publicações são encontradas discutindo estas questões. Além disso, o Rio de Janeiro é um estado referência, tanto no turismo doméstico quanto no internacional, sendo importante compreender sua experiência.

As condições para desenvolver o IOT-RJ por uma instituição pública de ensino, a Universidade Federal Fluminense (UFF), inserido em um programa de outra instituição pública, a Secretaria do Estado do Turismo do Rio de Janeiro (SETUR/RJ), apontou para alguns aspectos positivos e para fragilidades que levam a reflexão sobre as vantagens e limitações das metodologias empregadas, os sucessos e percalços na organização da pesquisa, a divulgação dos dados e sua alimentação.

Nesse sentido, para a elaboração do presente artigo foi desenvolvida uma pesquisa documental nos diversos relatórios técnicos do IOT-RJ (Rio de Janeiro, 2016), em documentos sobre as políticas públicas de turismo brasileiras e do Rio de Janeiro, revisão bibliográfica sobre o tema e observação direta do coordenador geral do projeto, do supervisor da pesquisa e de um dos coordenadores regionais.

$\mathrm{O}$ artigo está organizado em três subseções, a primeira trata do referencial teórico, que teve como foco a pesquisa exploratória, bibliográfica sobre o tema; a segunda explica o IOT-RJ; a terceira descreve e analisa como se desenvolveu o projeto no intuito de apontar dificuldades e propostas. Finalizando com as considerações finais.

\section{Breve contextualização sobre Inventários da Oferta Turística}

As definições de oferta turística estiveram, historicamente, presentes na literatura sobre o turismo no Brasil (Wahab, 1997; Sancho, 2001; Lage \&; Milone, 2001; Ignarra, 2013; Beni, 2018). Elas explicam a oferta turística como um conjunto de recursos, atrativos, infraestruturas, equipamentos e serviços turísticos de um destino turístico, que possa ser disponibilizado para satisfazer as necessidades de um público visitante, em uma determinada região, durante um determinado período. Portanto, a oferta turística se constitui do produto turístico colocado à disposição dos turistas em uma localidade turística.

Para se conhecer e poder gerenciar a oferta turística é preciso inventariá-la, o que se realiza originando um inventário. Martins (2006) entende o inventário como um documento contabilístico, que consiste em uma relação de bens que pertencem a uma pessoa, entidade ou comunidade. Derivando dos inventários, a palavra inventariação está relacionada ao ato de inventariar, descrever minuciosamente, registrar, relacionar e catalogar, geralmente, bens e mercadorias.

De acordo com o Instituto Brasileiro de Turismo - Embratur (Brasil, 1979), o inventário possibilita a produção de instrumentos para o planejamento, em nível nacional, regional e municipal, com objetivo de proteger, preservar e divulgar a oferta turística. A identificação da oferta turística propicia a definição de municípios e espaços turísticos, e o estabelecimento de novos núcleos de apoio à expansão turística, além de disciplinar a ocupação territorial, visando a preservação e divulgação desta oferta.

O inventário é a primeira etapa para a definição de um plano de desenvolvimento turístico de uma localidade, uma vez que, por meio de seus resultados, a gestão pública, visitantes, planejadores e iniciativa privada passam a obter uma visão do patrimônio turístico do município, "possibilitando a definição de prioridades para os recursos disponíveis e permitindo a análise do significado econômico do turismo e seu efeito multiplicador no desenvolvimento municipal, para posteriormente desenvolver o diagnóstico e prognóstico turístico" (Brasil, 2006, p.11). 
No Brasil, a preocupação com a informação turística esteve presente ainda no segundo quartel do século XX, mas de maneira muito incipiente. Em 1979, a Embratur (Brasil, 1979) faz uma proposta metodológica para a Identificação do Espaço Turístico Nacional seguindo os princípios formulados pelo Centro Interamericano de Capacitação Turística para América Latina (CICATUR), da Organização dos Estados Americanos (OEA) e da Organização das Nações Unidas para a Educação, a Ciência e a Cultura (UNESCO).

Segundo Paiva (1995), esta proposta deu origem ao documento intitulado "Inventário da Oferta Turística”, com edições em 1980 e em 1984. Esse documento, com ajustes, vem servindo, até o presente momento, como base para o modelo adotado na inventariação turística no Brasil e em muitos países latinoamericanos e europeus.

Bursztyn (2003) explica que, na década de 1990, já no contexto mais amplo da globalização e da competitividade entre destinos turísticos, implantou-se, sob a égide da orientação neoliberal vigente, o Plano Nacional de Turismo (PLANTUR), de 1996-1999. Para Trentin e Fratucci (2011), este plano contou com duas importantes ações, o Programa Regional de Desenvolvimento do Turismo (PRODETUR) e o Programa Nacional de Municipalização do Turismo (PNMT).

No PMNT foi criado um instrumento para a captação de informações turísticas, o Roteiro de Informação Turística - RINTUR (Brasil, 1999), que se originava da ideia de inventário turístico, para o preenchimento pelos órgãos públicos municipais. Este inventário deveria ser realizado de maneira participativa, com residentes.

O PRODETUR, iniciado na primeira metade da década de 1990, foi associado ao plano Brasil em Ação com o objetivo de promover a expansão do turismo no território brasileiro integrando a população local por meio da geração de emprego e renda. A área inicial de atuação do Programa, direcionou-se à região Nordeste do país e ao estado de Minas Gerais. O Programa reuniu centenas de projetos, especialmente para implementação e melhoria da infraestrutura, desenvolvimento institucional dos órgãos estaduais e municipais, responsáveis pelo turismo, e recuperação do patrimônio histórico e ambiental, financiados, pelo Banco Interamericano de Desenvolvimento (BID), bem como pelo Banco Nacional de Desenvolvimento Econômico e Social (BNDES), que possibilitou a contrapartida dos estados e municípios para adesão ao programa. Na segunda fase do PRODETUR o objetivo foi focado na melhoria da qualidade de vida nas localidades atingidas.

O sucesso de sua primeira e sua segunda fases fez com que o Programa fosse ampliado territorialmente, tornando-se mais complexo. Segundo Paiva (2010, p. 205), "No final dos anos 2000 o grau de complexidade do programa é bem maior. Cabe a cada polo turístico elaborar um Plano de Desenvolvimento Integrado do Turismo Sustentável (PDITS), que é avaliado pelo Ministério do Turismo (MTur)”. Nesse plano era previsto um diagnóstico estratégico da área e das atividades turísticas que demandava a análise da oferta turística, para identificação de "gargalos" a serem trabalhados. Assim, uma das necessidades era a inventariação da oferta, sua análise e proposição de ações estratégicas. Contudo, analisando as orientações, percebe-se que eram poucas informações que deveriam ser levantadas e, as mesmas, eram mais quantitativas. Ainda deve-se registrar que o grande desafio da época era inserir conceitos, até então, novos junto aos gestores estaduais e municipais de turismo, como planejamento participativo e sustentabilidade, já demandados para a elaboração do PDITS, apesar dos avanços alcançados pelo PNMT na mesma época.

Assim, entre 1970 a 2002, a informação foi um instrumento que definiu a seleção de municípios prioritários para as políticas públicas de turismo no âmbito federal e, para isso, teve importância o inventário nas suas diversificadas versões por oferecer a base para as análises de potencialidade que ranqueavam os destinos e, em tese, seria mecanismo de distribuição de recursos.

Com a mudança no governo e a criação do Ministério do Turismo (MTur), em 2003, a partir do Programa de Regionalização do Turismo, estabelecido no PNT - 2003-2007 (Brasil, 2007), o foco da política de turismo no município altera-se para a região. 
Também com a criação do MTur (Brasil, 2006), detecta-se a necessidade de readequar as estratégias de inventariação da oferta turística vigentes ao novo modelo de desenvolvimento proposto para o turismo no País. Para este organismo, não existia uma estratégia definida para a divulgação dos resultados obtidos com a inventariação e nem padronização para apresentação das informações coletadas nos diferentes processos de inventariação realizados no País, ou mesmo, um instrumento de pesquisa eficiente para a coleta de dados. Por isso, no PNT 2003-2007 foi instituído um módulo operacional denominado de Sistema de Informações Turística (SIT), que se manteve nos PNT até 2016.

Para a implantação do SIT no âmbito do Projeto Inventário da Oferta Turística - INVTur, os instrumentos de pesquisa foram readequados e um banco de dados criado. O Projeto-Piloto foi aplicado no Rio Grande do Sul para o aprimoramento do material elaborado pela EMBRATUR e na introdução de novas abordagens e conceitos. O lançamento nacional do projeto ocorreu em 2006 e, em 2010, uma nova aplicação do material foi realizada a partir do convênio firmado com o Instituto para o Desenvolvimento da Economia, do Indivíduo, do Ambiente e da Sociedade - IDEIAS, no estado do Rio de Janeiro. Sua aplicação resultou em ajustes no INVTur (Rio de Janeiro, 2016). Assim, durante o período de 2006 a 2011, muitos municípios brasileiros fizeram seus inventários com esta orientação e, seus dados foram disponibilizados pelo banco de dados do INVTur.

Atualmente, o INVTur ainda está na página do MTur, mas não é possível acessar seu banco de dados. Não obstante, os materiais utilizados para as pesquisas continuam disponíveis e o modelo de instrumentos de coleta de dados, reestruturados pelo MTur, em 2011, ainda são os indicados para a realização de inventários em todos os estados nacionais, apesar de nos últimos PNT (2014-2017 e 2018-2022) o INVTur não ser mais apresentado entre os programas e projetos previstos. No entanto, subentende-se que as informações da oferta turísticas estão no Sistema Nacional de Informações Turísticas (SNIT) previsto no Plano Nacional Estratégico de Estatística Turística.

\section{O Inventário da Oferta Turística dos Destinos Turísticos do Rio de Janeiro: DESCRIÇÃO DA EXPERIÊNCIA E PERSPECTIVAS DE UMA ANÁLISE}

Desde a segunda década do século XXI, desenvolve-se o PRODETUR - Rio de Janeiro, um programa do MTur, por meio da SETUR RJ, que tem como um de seus pilares a inventariação da oferta turística de uma gama de municípios do estado, o que resultou no projeto IOT-RJ. Segundo a SETUR RJ/UFF (Rio de Janeiro, 2016), as experiências de inventariação, até então, desenvolvidas no estado do Rio de Janeiro, foram pontuais e descontínuas, além de não se ter padronização, acesso democrático aos dados e política de monitoramento e atualização. Destarte, o novo IOT, realizado pelo PRODETUR, deveria suprimir estas lacunas.

Assim, a partir da perspectiva enunciada, abriu-se uma licitação para execução do projeto que teve a UFF como vencedora. O Núcleo de Projetos de Turismo, Hotelaria e Serviços (NUPTHS), da Faculdade de Turismo e Hotelaria (FTH), foi o organismo responsável pelo seu desenvolvimento com a colaboração de docentes e discentes da Universidade Federal Rural do Rio de Janeiro (UFRRJ), do Centro Federal de Educação Tecnológica Celso Suckow da Fonseca (CEFET Campi Nova Friburgo e Petrópolis), do Consórcio Centro de Educação Superior a Distância do Estado do Rio de Janeiro (CEDERJ Polos de Resende e de Angra dos Reis) e da Escola Técnica Estadual (Etec) Helber Vignoli Muniz, em Saquarema (IOT-RJ, 2018).

A definição dos municípios participantes, deu-se pela gestão do PRODETUR RJ, que se pautou nos documentos do Plano de Desenvolvimento Integrado do Turismo Sustentável (PDITS) Serra e Litoral, desenvolvidos em 2010 (Rio de Janeiro, 2010). Dos 42 municípios pertencentes ao PDITS, 23 foram escolhidos (Figura 1). 
Compõem as regiões e municípios do Polo Litoral contemplados pelo projeto: Região Metropolitana (Rio de Janeiro e Niterói), Costa do Sol (Araruama, Armação dos Búzios, Arraial do Cabo, Cabo Frio, Casimiro de Abreu, Iguaba Grande, São Pedro da Aldeia) e Costa Verde (Angra dos Reis, Mangaratiba, Paraty, e Rio Claro), e, do Polo Serra: Serra Verde Imperial (Cachoeiras de Macacu, Nova Friburgo, Petrópolis, Teresópolis), Vale do Café (Barra do Piraí, Rio das Flores, Vassouras e Valença) e Agulhas Negras (Itatiaia e Resende).

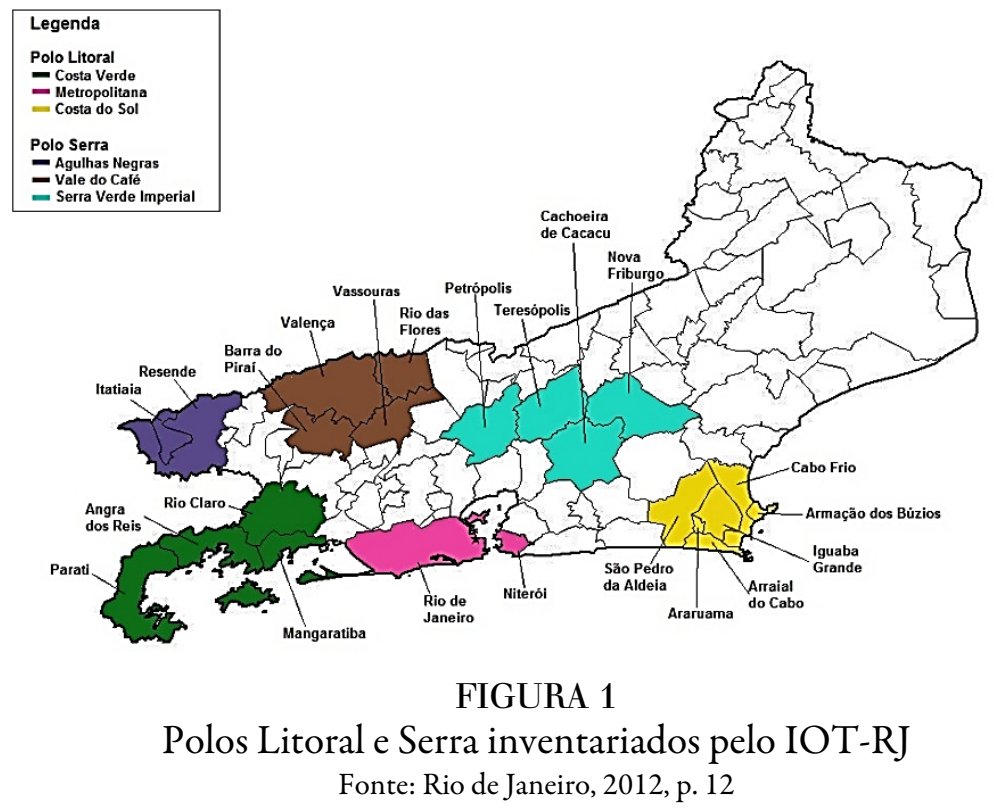

O IOT-RJ foi idealizado com um banco de dados para alimentar o Sistema de Informações e Estatísticas Turísticas do Estado do Rio de Janeiro e sistematizar instrumentos para a pesquisa da oferta, em consonância com o padrão do MTur, reestruturado em 2011.

Seus objetivos foram armazenar, sistematizar, tratar, atualizar as informações coletadas. Após esse primeiro passo, disseminá-las nas instâncias governamentais, estudantes, empresários, pesquisadores, comunidade e turistas para que tivessem acesso aos resultados do projeto, visando subsidiar avaliações e estabelecer as prioridades necessárias para a aplicação dos meios humanos e econômicos no desenvolvimento do setor turístico.

O resultado destas ações possibilitaria utilizar melhor os recursos públicos e evitar sobreposições de ações; realizar análises quantitativas e qualitativas dos empreendimento de cada setor turístico; conhecer a cadeia de fornecedores; ter os atrativos catalogados, descritivamente e visualmente; estabelecer roteiros turísticos e calendários de eventos; distinguir as características e a dimensão da oferta que podem levar ao desenvolvimento do turismo, com sustentabilidade e gerar relatórios consolidados sobre o turismo fluminense.

Para o desenvolvimento do projeto foram realizadas etapas de planejamento, executação e avaliação, estabelecidas em 12 passos, e, cada um deles, resultou em um produto entregue e avaliado pelo contratante, seguindo um calendário proposto no Produto 1, Plano de Trabalho, que trazia a apresentação da proposta de desenvolvimento da pesquisa, apontando os métodos, prazos e recursos.

Na sequência, o Produto 2, Agenda de Compromisso e Responsabilidades, foi apresentado, no entanto, a agenda criada em 2015, não se cumpriu de forma plena devido a vários fatores que levaram a postergação do início do projeto, o que recaiu em replanejamento, nem sempre favorável.

Ao planejar os dias de pesquisa de campo, levou-se em consideração a baixa temporada e as condições climáticas. Com o atraso no pagamento dos produtos entregues, por problemas internos à SETUR RJ, o 
campo teve que ser alterado e nem sempre o período de pesquisa era o ideal. Ao modificar uma das fases, as demais ficaram comprometidas.

O Produto 3, Plano de Comunicação, tinha por objetivo gerar informações, sensibilização e envolvimento dos municípios junto ao projeto (incluindo a assinatura do termo de compromisso). Assim, para estas ações, primeiro foi contratada uma empresa de comunicação que desenvolveu a marca e os materiais de identidade visual para o projeto e para cada subpolo, além dos instrumentos que foram usados durante a pesquisa, como crachás, coletes, entre outros. A empresa cumpriu o prazo previsto, de acordo com a proposta e aprovação do contratante.

Com profissionais de marketing, de desenvolvimento de sites da FTH e um estudante, com curso de marketing digital, criou-se uma rede de comunicação para informar, sensibilizar e registrar todas as ações do projeto. A rede resultou em produtos como site, blog, página no facebook e flicker e assinaturas no Instagram e twitter, alimentados com notícias sobre o andamento do projeto. Uma assessoria de imprensa foi incorporada e o projeto teve grande dimensão na mídia nacional, estadual e municipal.

Com tais ações de comunicação, percebeu-se que se por um lado tais estratégias resultam positivamente, por divulgar as ações do turismo e favorecer a participação da comunidade, por outro são bastante improdutivas, pois aparentam que o inventário é o único acontecimento necessário e não um processo sistemático de planejamento contínuo.

Em relação a operacionalização da pesquisa, houve três etapas: a primeira deveria sensibilizar a comunidade a participar. Esta ação seria realizada por meio de mídias locais e regionais, e contava-se com o auxílio dos organismos públicos e privados do turismo local e da SETUR RJ. Em alguns municípios esta ação foi muito eficaz, obtendo expressiva adesão. Contudo, houve municípios em que esta parceria não ocorreu, interferindo no resultado da pesquisa.

A segunda etapa, consistia em organizar as oficinas de convalidação de dados levantados no gabinete para serem pesquisados no campo. Todo processo de convite, aceite, participação, colaboração e retorno, precisava ser realizado, acompanhado e avaliado para que a oficina tivesse adesões e bons resultados. Esta ação foi dividida entre a equipe da UFF, da SETUR RJ e dos municípios. Por estar atrelado e dependente do poder público estadual e local, o resultado da adesão teve pouco controle por parte da UFF, executora do projeto, e, em alguns subpolos, a participação não obteve um bom resultado, dificultando o processo.

A última etapa, tratava-se do agendamento das entrevistas e visitas aos locais a serem pesquisados. Ao término da convalidação da pesquisa documental, foram geradas listas de nomes e endereços que deveriam ser contados para o agendamento. Enviou-se correspondências eletrônicas ou foram realizadas ligações telefônicas solicitando a marcação da entrevista e, em muitos atrativos ou equipamentos e serviços turísticos, a ausência de dados de contato (telefone, endereço e e-mail ou rede social) impediram o agendamento. Várias páginas de sites oferecem apenas como forma de comunicação o "fale conosco", como espaço para deixar mensagens. Usou-se este contato, no entanto, recebeu-se poucos retornos. Outros contavam com telefone e/ ou e-mail publicados, mas, que estavam desatualizados.

Em alguns municípios, os membros do trade alegaram desconhecer o projeto e não recebiam os pesquisadores sem agendamento. Nestas situações, ou quando o pesquisador se dirigia para o local sem estar com pesquisa marcada, conversava-se com os responsáveis explicando o que era o projeto e procurava-se agendar a pesquisa dentro do prazo estabelecido para aquele município. Esta ação demandava atividades extras, tanto em tempo, quanto em custo, não sendo a melhor forma para sua realização.

Após concluído o período estipulado para a pesquisa no município, e verificado algum insucesso, um novo esforço era realizado. Normalmente, visitava-se entre duas a três vezes o local, todavia, caso ainda não conseguisse a entrevista, a pesquisa era descartada. Isto poderia acontecer também em locais agendados. Ao chegar no local, o responsável alegava que não poderia atender e solicitava outra hora ou dia. Sempre se procurava agendar novamente, mas em alguns casos, não foram possíveis a inventariação do estabelecimento por causa do tempo estipulado para cada subpolo. 
O Produto $5^{[1]}$, Elaboração e edição do manual do pesquisador e dos formulários da pesquisa, consistiu na confecção de um manual do pesquisador, contendo todos os procedimentos da pesquisa, oficinas de treinamento de equipes para a pesquisa documental e de campo (pesquisa e preenchimento de formulários), orientação para fotografar os equipamentos, serviços e atrativos, captar dados com GPS, armazenamento, entre outros.

O desenvolvedor do software contratado preparou um manual para o preenchimento dos formulários e os monitores colaboraram com mais explicações. Este manual foi incorporado ao manual do pesquisador e empregado no treinamento dos pesquisadores em cada um dos subpolos.

Os formulários escolhidos para o projeto, como determinava na licitação, foram os do INVTur, com inclusão de algumas questões, como, por exemplo, dados sobre a maturidade digital e sobre os trabalhadores do setor. A pesquisa não abarcou todos os formulários do INVTur, somente os formulários $\mathrm{B}$ e C foram solicitados por contrato. Especificamente no caso do município do Rio de Janeiro, no formulário B, apenas foram pesquisados os equipamentos e serviços de meios de hospedagem.

No Produto 6, Seleção e Treinamento da Equipe, a definição de equipe e a forma de seleção e o treinamento de pesquisadores já estava estipulada na proposta da licitação. A equipe foi formada pelos cargos demonstrados na figura 2

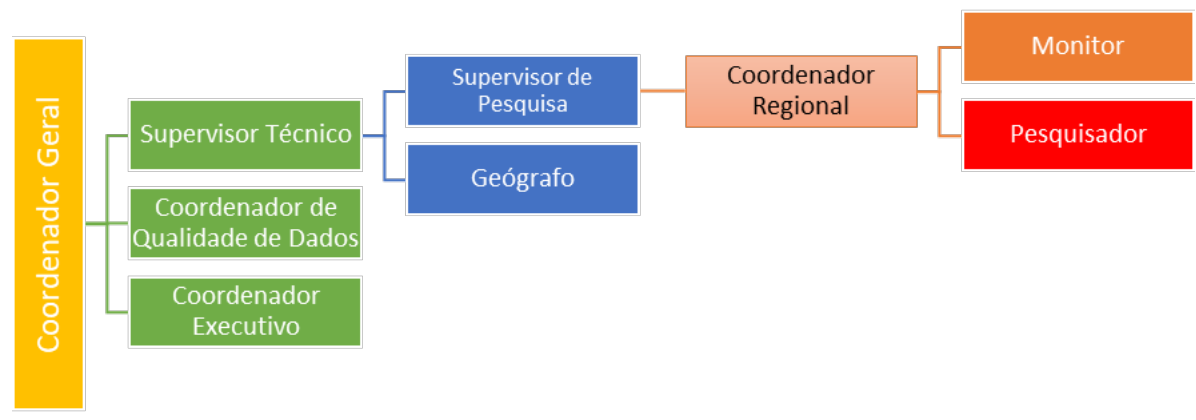

FIGURA 2

Equipe de Pesquisa do IOT-RJ

Fonte: Rio de Janeiro, 2016.

No espaço do NUPTHS, realizou-se todas as ações necessárias para que a qualidade dos dados, a logística, o controle administrativo e financeiro e os recursos humanos fossem executados/assistidos. Também se responsabilizou pelo design gráfico e revisão dos produtos entregues, atuando sob a supervisão do coordenador geral que fez a ponte entre esta equipe e a pesquisa. Operaram, ainda, revisores docentes da FTH licenciadas em letras, e, a já citada, equipe de comunicação e marketing da FTH. Contou-se com um coordenador geral, um coordenador de qualidade de dados e um coordenador executivo, além de professores e estagiários da FTH nos seus três níveis de formação graduação, MBA e mestrado.

Em cada subpolo, uma equipe ficou responsável pela pesquisa de documental (gabinete) e outra pela pesquisa de campo. Para tanto, na pesquisa documental foram selecionados monitores e pesquisadores no quadro de estudantes e egressos dos cursos de Turismo e Hotelaria da UFF e do curso de Turismo da UFRRJ. As equipes foram definidas em janeiro de 2015 e iniciaram a pesquisa documental em fevereiro do mesmo ano, sendo supervisionadas por um docente da UFF.

Já para a pesquisa de campo foram criadas equipes formadas por 20 pesquisadores, um monitor e um coordenador regional. Cada equipe realizou a pesquisa durante duas semanas no subpolo, sendo que com exceção dos subpolos do Vale do Café e Agulhas Negras, houve a atuação de duas equipes. Alguns pesquisadores e monitores participaram da pesquisa em mais de um subpolo. Estas equipes foram criadas, na medida do possível, envolvendo pesquisadores e monitores associados a instituições de ensino de atuação regional, tanto pelo conhecimento maior sobre o território quanto por custos mais favoráveis, o que 
ocasionou maior possiblidade de troca de conhecimentos e oportunidades para os estudantes dos cursos de turismo e hotelaria envolvidos.

Em março de 2015 houve o lançamento oficial do projeto, mas a assinatura do contrato só veio a ocorrer em setembro, por questóes relacionadas a problemas internos da SETUR RJ. Mesmo sem assinar o contrato, as equipes continuaram com suas atividades. Em junho houve uma diminuição no ritmo, e até paralização das atividades, por falta de pagamento da bolsa dos pesquisadores, problemática que discutiremos mais adiante. Esta ausência de pagamento, acabou gerando alta rotatividade de pesquisadores, o que alterou a ideia inicial, de que a equipe que participasse da pesquisa documental também participaria da pesquisa no campo. Isso foi possível em apenas alguns casos, como parte da pesquisa no Rio de Janeiro e em Niterói.

O treinamento inicial foi realizado com o supervisor da pesquisa, coordenadores regionais e os monitores, além da empresa desenvolvedora do software. Depois de um tempo utilizando o software, outra reunião foi marcada para acertos e sugestóes dos monitores com os desenvolvedores. Sendo todo processo acompanhado pela supervisão da pesquisa e o coordenador executivo.

Mesmo com todo processo de treinamento, muitas dúvidas ainda pairavam na hora da pesquisa de campo. Para facilitar a comunicação e sanar as dúvidas foram montados grupos de comunicação rápida em redes sociais por subpolo, que auxiliaram na circulação de informações entre os pesquisadores e administradores do projeto.

Retomando a discussão sobre o Produto 4, Diagnóstico da situação atual e proposição de estratégias de aplicação do inventário, pela dimensão da pesquisa, por questões ambientais, por limitação de tempo e pela praticidade, de armazenar e tratar os dados, optou-se por realizar a pesquisa utilizando meios digitais. Esta experiência já havia ocorrido em alguns inventários como de Ilhéus (Bahia, 2011), embora, nesta experiência, nem todos os dados foram obtidos por meio digital.

$\mathrm{Na}$ escolha do software e dos equipamentos para o levantamento dos dados poderia se optar por dois caminhos: desenhar um sistema próprio ou adaptar um sistema já existente. Em janeiro de 2015, a SETUR $\mathrm{RJ}$ sinalizou que as pesquisas de campo seriam iniciadas em fevereiro. Assim, pelo tempo disponível, não seria possível desenhar um sistema e, desta forma, escolheu-se por adaptar um existente. A opção recaiu sobre o Census and Survey Processing System (CSPro6), software gratuito usado no Censo Americano. Ele permitiu que fossem instalados os formulários do INVTur nos computadores e que estes dados pudessem estar nos tabletes para a pesquisa de campo.

Um ponto importante foi o software rodar off-line, por não haver conexão de internet em muitos lugares da pesquisa. Todavia, a escolha pelo CSPro como software para o banco de dados, que a princípio se mostrou a melhor opção por causa do tempo, acabou sendo um dos maiores dissabores do projeto. Durante a pesquisa, o software se demonstrou pouco amigável e dependente, o tempo todo, de intervenção do desenvolvedor, o que foi um complicador pelo número de pesquisadores e locais envolvidos. Muitos dados pesquisados não foram salvos ou se perderam, causando um retrabalho, ou mesmo, perda da informação.

A quantidade de dados envolvida no projeto seria muito grande, por isso, para o armazenamento e partilha de arquivos, empregou-se o uso do Dropbox, que é baseado no conceito de "computação em nuvem" e possibilita trabalho em equipe, com segurança na manutenção dos dados e seu compartilhamento.

Os passos da pesquisa documental, adotados pelo IOT-RJ, não destoaram da prática realizada nas pesquisas brasileiras de inventários da oferta turística. Primeiro houve o treinamento de pesquisadores, depois montagem de equipes por subpolo de pesquisas, pesquisa exploratória para seleção de acervos, fontes e referências para a pesquisa.

Para conseguir a base de dados, a princípio, migrar-se-ia os inventários realizados nos municípios de Armação dos Búzios, Mangaratiba, Niterói, Paraty e Petrópolis pelo Instituto Ideias, no Projeto-Piloto do INVTur de 2010 e Quissamã concretizado pela UFF e inserido no sistema MTur. Ao procurar dados sobre estes municípios, em 2015, a partir do comando "Buscar" era possível identificar o nome do município, a data de abertura do inventário, a situação e a data de fechamento. O de Quissamã era o mais antigo, iniciado 
em 2007 e finalizado em 2008, na sequência Niterói, iniciado em 2009 e finalizado em 2011, Armação dos Búzios, Petrópolis e Paraty, iniciados em 2010 e finalizados em 2011, e Mangaratiba, iniciado em 2011 e finalizado em 2012.

Quando se consultava o SIT, no item relatórios, apenas os municípios de Armação dos Búzios, Paraty e Petrópolis apresentavam o documento e somente os dados de Petrópolis estavam acessíveis. Mesmo assim, poucas eram as informações disponíveis, como, por exemplo, nos Serviços e Equipamentos de Hospedagem se verificava apenas o nome fantasia/comercial, o nome da rede, o endereço, o site, o e-mail, o período de funcionamento e a quantidade de unidades básicas (UH's) adaptadas para deficientes.

O Instituto Ideias manteve um portal de turismo e inventários de municípios para as prefeituras que pagassem para hospedá-los. Como muitas prefeituras não tinham recursos para pagá-los, seus dados não foram publicitados, ou foram, apenas em um breve período. Quando se iniciou a pesquisa de gabinete do IOT-RJ, apenas São Pedro da Aldeia mantinha o seu inventário no portal do Ideias ${ }^{[2]}$.

A solicitação direta aos representantes públicos do turismo dos municípios envolvidos, para disponibilizar formulários em papel e/ou dados consolidados da pesquisa do Instituto Ideias ou de outra fonte, encontrou obstáculos que somente poderiam ser ultrapassados após a assinatura dos termos de compromisso entre os municípios, SETUR RJ e UFF. Com o atraso das assinaturas destes termos, o pedido que ocorreria no início da pesquisa documental, somente poderia ser feito quando esta fase da pesquisa estava no final. Em vista disso, fez-se algumas parcerias, não oficiais, de repasse destes materiais entre os coordenadores de pesquisa e os órgãos municipais de turismo em Angra dos Reis, Niterói e Petrópolis, bem como foram disponibilizados dados por professores responsáveis pelas pesquisas realizadas em atividades didáticas no Curso de Turismo da UFRRJ nos municípios de Itatiaia, Valença e Vassouras.

Com esta dificuldade, a primeira proposta que seria fazer a migração dos dados do inventário do MTur para o banco de dados do IOT-RJ não se realizou. Portanto, praticamente, construiu o banco de dados desde o início, exigindo mais tempo e trabalho, apesar do investimento anterior feito pelo MTur, SETUR RJ e órgãos municipais.

Assim, o primeiro passo foi realizar uma pesquisa exploratória de gabinete, cujos dados foram passados para planilhas desenvolvidas no software MS Excel. Os monitores distribuíram estas planilhas para os pesquisadores de seu subpolo iniciarem a pesquisa documental e os dados eram armazenados em pastas individuais no Dropbox dos pesquisadores que tinham metas quantitativas e temporais para o preenchimento dos dados. O controle realizado pelo monitor era diário e semanal, e o cumprimento das metas influenciou no pagamento da bolsa do pesquisador que girou em torno de $\mathrm{R} \$ 1.200,00$ reais $^{[3]}$ por cada contrato.

Foram relatadas pelos monitores muitas dificuldades na coleta dos dados, principalmente nos atrativos turísticos, equipamentos e serviços de agências de viagens e de alimentos e bebidas. De uma maneira geral houve indisponibilidade de dados para a consulta em todas as áreas a serem pesquisadas, observando que quando estavam acessíveis, apresentavam-se incompletos. Percebeu-se que os dados disponíveis, em poucos municípios, encontram-se organizados, atualizados e acessíveis.

O buscador Google foi usado para obter informações iniciais sobre os locais, contatos de referência, horário de funcionamento e se estava aberto. Quando não se tinha certeza de o local de pesquisa estar funcionando, consultou-se o Facebook, Booking, Instagram ou TripAdvisor para verificar se as datas das fotos ou avaliações postadas eram recentes, indicando que poderia estar aberto ao público. Outras vezes, os blogs de viajantes ou de aventureiros davam dicas de lugares já visitados ou de lugares potenciais, bem como contatos. As redes sociais e os sites foram muito úteis nesta fase da pesquisa.

Usou-se as fontes de pesquisas oficiais e de outros organismos, além do Sistema de Cadastro de Pessoas Físicas e Jurídicas que atuam no Turismo (Cadastur), planos diretores dos municípios, livros, teses, artigos científicos, guias impressos e virtuais, publicações oficiais, organismos internacionais, nacionais, estaduais e municipais referentes às áreas de turismo, meio ambiente, cultura e economia, aplicativos de turismo, associações, organismos internacionais, nacionais e locais voltados à cultura e ao meio ambiente, organismos 
de categorias profissionais e seus sindicatos, sites de buscadores, blogs, páginas do Facebook de empresas e organismos relacionados ao turismo, folders de comunicação turística, empreendimentos isolados de turismo, entre outros.

Quanto ao Cadastur, deve-se ressaltar que, na época da pesquisa, o número de equipamentos, serviços e atrativos cadastrados tinha uma representação muito pequena. Com a exigências para a inclusão ou permanência de um município no Mapa do Turismo Brasileiro e a fiscalização, em 2018, os cadastros regulares aumentaram ${ }^{[4]}$.

Ao término da coleta, convalidou-se internamente os dados armazenados e, na sequência, estes foram sistematizados e transformados no primeiro banco de dados do qual extraíram-se planilhas utilizando o software MS Excel. Estas foram empregadas para as oficinas de convalidação e, posteriormente, encaminhadas para o geógrafo da equipe realizar o georrefenciamento dos dados e a confecção de mapas que auxiliariam no planejamento da pesquisa de campo (Parte do Produto 9).

O levantamento destes dados, mesmo com todo acesso aos dados digital, mostrou a necessidade de se ter um sistema de informações e este ser alimentado de maneira contínua com a formação de uma rede de dados, evitando ônus temporal para a pesquisa e facilitando a sua atualização.

No final desta fase, chegou-se a um número de 10.342 formulários para serem pesquisados em campo, e estes foram levados para as oficinas de convalidação (uma por subpolo) que seguiram um check list desenvolvido para padronização de sua realização em campo. Os dados consolidados da pesquisa documental foram transformados em materiais para oficinas no modelo participativo. Listagens, fotos e dados foram disponibilizados no formato de painel por subpolos e grupos de participantes de cada município avaliavam os dados decidindo se era ou não passível de serem pesquisados, além de incluírem sugestões de novos dados.

Esta etapa, a participação dos residentes, pode ser considerada a mais significativa no planejamento da pesquisa, respeitando o aval de quem vive no local e que turismo deseja para seu município. Ouvir, respeitar e acatar o que os moradores querem que esteja presente no inventário é importante para a corresponsabilidade no desenvolvimento do turismo. No entanto, há também estudos acadêmicos e científicos que embasam a teoria da Oferta Turística e estes devem, da mesma forma, ser considerados na definição dos itens do inventário.

Os parâmetros utilizados para a aceitação ou não da sugestão dos moradores foram critérios retirados da própria metodologia, respeitando o glossário construído para identificar o que significa cada um dos itens a serem inventariados. Um dos parâmetros mais difíceis, refere-se aos estabelecimentos de alimentos e bebidas. Neste caso, sugeriu-se que o pesquisador observasse se os estabelecimentos tinham algo diferenciado que pudesse interessar aos visitantes, localização próxima a atrativos ou serviços e equipamentos turísticos, ser um local que recebe turista e/ou tem uma gastronomia bem avaliada pelos comensais.

As convalidações não terminaram nas oficinas, em algumas regiões houve a necessidade de continuar o trabalho junto a gestores municipais e formadores de opinião, em função da pequena participação em algumas oficinas convalidação. Assim, foi marcada novamente uma reunião com o organismo de turismo, alguns participantes do trade, o coordenador regional e o monitor. Estas reuniões ocorreram nos municípios de Paraty, Rio Claro, Iguaba Grande, São Pedro da Aldeia e Araruama. Não se conseguiu reunir com os municípios de Valença e Rio das Flores.

Ao final deste processo, notou-se o aumento, em todos os subpolos, em quase três mil formulários (Tabela $1)$. 
TABELA 1

Número de formulário pesquisa documental (fase 1) e convalidação (fase 2)

\begin{tabular}{lcccl}
\hline Subpolos & Fase 2 & Fase 3 & \# & \% \\
\hline Agulhas Negras & 503 & 627 & 124 & 24 \\
\hline Costa do Sol & 2.194 & 2.442 & 248 & 12 \\
\hline Costa Verde & 2.985 & 3.523 & 538 & 18 \\
\hline Metropolitana & 2.371 & 2.768 & 397 & 16 \\
\hline $\begin{array}{l}\text { Serra Verde } \\
\text { Imperial }\end{array}$ & 1.663 & 2.094 & 431 & 26 \\
\hline Vale do Café & 1.158 & 1.693 & 535 & 46 \\
\hline Total/média & 10.874 & 13.147 & 2.273 & 23 \\
\hline
\end{tabular}

Fonte: Produto 4 - Diagnóstico do Inventário da Oferta Turística, IOT-RJ, 2016.

Verificou-se que ocorreram aumentos mais significativos nos subpolos do Vale do Café, Serra Verde Imperial e Agulhas Negras. Em média houve 23\% de aumento de formulários em todos os subpolos. Corroborando com a afirmação da importância dos residentes no processo de inventariação.

Após as fases descritas anteriormente, foi realizada no município de Niterói um pré-teste da pesquisa de campo, base para a elaboração do Produto 7, referente à fase 3.

\section{AplicaçÃo do Inventário da Oferta Turística}

O pré-teste foi fundamental para ajustar a metodologia e a logística de campo, no entanto, também apresentou limitações. As facilidades advinham de ter como base de apoio o NUPTHS, que fica em Niterói, e, também, maior facilidade de transportes, uma vez que a garagem dos veículos da universidade estar nesta cidade. Por outro lado, não se ateve que outros problemas poderiam ocorrer em outros destinos, como a questão da velocidade da internet, problemas com o alojamento e a necessidade de substituição de veículos rapidamente.

Assim, no pré-teste e mesmo no trabalho de campo nas demais localidades, o uso dos tablets demonstrou ser uma opção acertada, no entanto; em alguns lugares seu uso era arriscado pela insegurança presente. A estratégia adotada foi um pesquisador ficar observando o ambiente, enquanto o outro registrava os dados.

Ressalta-se que em vários subpolos a conexão, embora existente, era de baixa velocidade de transmissão de dados. Como os dados captados pelos tablets deveriam, todas as noites serem transferidos para Dropbox, necessitava-se de acesso à internet com boa velocidade pelo volume de dados. Esta questão fez com que, em alguns casos, os dados fossem transmitidos a um computador via cabo e, a partir deste computador, para o Dropbox. Esta opção tornou o processo demorado, levando o monitor, já cansado de todo trabalho da pesquisa realizado durante o dia, permanecer horas transmitindo os dados. Estas podem ser umas das questões não previstas que dificultaram o andamento da pesquisa.

Ademais, a escolha do Dropbox foi positiva, sendo essencial para o armazenamento e para a troca entre os envolvidos no projeto, como também para a segurança dos dados (back up)

Ainda no pré-teste, observou-se que havia incompatibilidade entre o software instalado e os tablets, sendo necessária a compra de tablets mais modernos. Contudo, o projeto ainda não tinha recursos para tanto. Levando em consideração que houve mudança na programação por causa do atraso na assinatura de contrato $^{[5]} \mathrm{e}, \mathrm{com}$ isso, as pesquisas em alguns subpolos tiveram que ser simultâneas, exigindo um maior número de equipamentos.

Esta ocorrência com o software e o equipamento afetou a pesquisa no município de Niterói, parte do município do Rio de Janeiro e do subpolo de Agulhas Negras. Com a compra de novos tablets o problema foi parcialmente sanado. 
Também se notou que a marcação de visitas não estava funcionando como o previsto, fazendo os pesquisadores voltarem mais de uma vez aos locais de pesquisa, como já destacado quando se discutiu sobre comunicação e logística.

Determinados questionamentos surgiram durante a aplicação do pré-teste que exigiu padronização das informações, como a participação de serviços e equipamentos de alimentos e bebidas, já citado, e o caso dos equipamentos de lazer e recreação que somente foram pesquisados os clubes que permitiam a visita de turistas.

Para os equipamentos e serviços turísticos de hospedagem, definiu-se por não serem pesquisados locais em que a frequência se destina a encontro de casais, com pagamentos por horas. Pensóes com contratos mensais, também foram desconsiderados por serem locais de moradia semipermanente, o que dificulta o contrato com os turistas em estadas menores. Os hotéis de trânsito também foram descartados por não serem abertos aos turistas, bem como os aluguéis de residências pela dificuldade em realizar a pesquisa por causa da sistematização das fontes, já que muitos locadores particulares fazem estes aluguéis diretamente com os clientes, sendo uma pesquisa muito extensa para a qual o projeto IOT RJ não teria tempo e nem recursos financeiros.

Foram excluídos de visitação em campo os atrativos naturais que estavam poluídos, como rios, córregos e cachoeiras. Porém, foram considerados os poluídos que permitem a visitação parcial como a Baía da Guanabara, os Lagos da região de Jacarepaguá no Rio de Janeiro, entre outros. Os relevos de acesso difíceis de serem explorados e os que ficam em locais sem segurança para a pesquisa não foram pesquisados.

Visitou-se espaços para eventos existentes em hotéis, centros de convenções, espaços em instituições de ensino, pavilhões e recintos de feiras, palcos fixos em parques. Não se visitou espaços alternativos ou temporários, por serem montados apenas na ocasião do evento.

Quanto aos atrativos culturais, por exemplo, os religiosos não foram todos contemplados. Escolheuse aqueles que têm, por parte da apreciação estética, aspectos avaliados pelos organismos responsáveis pela salvaguarda do patrimônio ou que se inserem em inventários culturais, ou pelo aspecto de culto que representam um local de destaque para aquela religião ou seita. Já no caso de instituições culturais como museus e centros culturais, todos foram selecionados para serem pesquisados. Atenta-se que centros comunitários voltados para o desenvolvimento cultural dos residentes, que normalmente não se destinam a visitação turística, foram definidos como potenciais.

No Produto 8, referente ao Relatório de atividades de campo, foram descritas todas as atividades realizadas entre o dia 18 de janeiro a 01 de agosto de 2016. Estes oito meses no campo foram ininterruptos. Quando uma equipe acabava, outra iniciava ou, concomitantemente, estavam duas equipes em campo. Foi um dos períodos mais complexos da pesquisa, por envolver o preparo do campo, a comunicação com o poder público e com a comunidade (incluindo o trade), organização da logística do campo, ocorrida em cada subpolo de maneira diversa, seleção e treinamento de pesquisadores, mapeamento e roteirização dos municípios para o desenvolvimento da pesquisa, inserção de dados nos tablets, entre outras ações que culminaram na experiência do campo.

Ao chegar ao campo, nem sempre todo o planejamento e o preparo anterior conseguiam obter o sucesso que se esperava. As equipes se depararam com muitos desafios gerados por questóes endógenas e exógenas ao projeto, como a citada questão do uso dos tablets ou a questão climática. Inicialmente, para a escolha das datas, levaram-se em conta a baixa temporada e o período menos chuvoso em cada subpolo. No entanto, com os problemas de repasse de recursos por parte dos contratantes, foi preciso acertar a agenda para datas que coincidiram com dias de muita chuva, atrapalhando o trabalho.

Em muitos municípios, como Rio de Janeiro, Angra dos Reis, Cabo Frio e Paraty as equipes se depararam com problemas de segurança, como já destacado, como o fechamento de bairros por traficantes, tiroteios, intimidação da milícia, assalto e agressões físicas, além da desconfiança que estiveram presentes no dia a dia das pesquisas. Quando se sabia que a região da pesquisa teria algum problema, esta foi evitada, uma vez que para os organizadores da pesquisa a integridade do pesquisador veio em primeiro lugar. 
A pesquisa ainda passou por um outro problema relacionado ao trade turístico. Alguns estabelecimentos, em vários municípios, não quiseram participar. Atribuiu-se esse posicionamento a algumas causas como: a ausência de associativismo que permitiria a divulgação e o engajamento dos profissionais de turismo no processo de planejamento do turismo; a falta de compreensão dos profissionais que atuam no turismo sobre a importância em se realizar pesquisas para obter dados que permitam análises e estudos; incompatibilidade de ideias políticas entre o empreendedor e a gestão municipal ou estadual, levando alguns membros do trade a não contribuírem; a ocorrência, anterior, de inventários que não trouxeram resultados aguardados, portanto causaram desilusão em alguns envolvidos.

O engajamento do poder público também variou muito de município para município e de subpolo para subpolo. Alguns foram muito participantes e assessoraram as equipes, outros não tiveram quase nenhum interesse.

As condições de acesso precários, principalmente nas zonas rurais, também foram aspectos que atrapalharam as coletas de dados. Muitos municípios têm a maioria de seus atrativos nestas áreas que ainda não estão preparadas para receber os turistas. Um problema pontual ocorreu no Rio de Janeiro: as obras para os Jogos Olímpicos de 2016 fizeram com que o tempo de deslocamento durasse até quatro horas entre uma região e outra, o que atrasou a pesquisa e alterou o calendário e, em alguns casos, chegando a não se conseguir realizá-la.

Após estas considerações relativas aos problemas, apontam-se resultados positivos obtidos. Pode-se considerar um destes aspectos a inclusão de 152 pesquisadores de diversas instituições de ensino, que tiveram a oportunidade de realizar um trabalho como pesquisador remunerado e com todo apoio técnico, o que contribui para a formação de novos profissionais de turismo com experiência da pesquisa no campo, além daquela realizada em muitos cursos de Turismo na disciplina de Planejamento Turístico.

A monitoria da pesquisa foi efetivada por bacharéis de turismo, com pouco tempo de graduação, dandolhes experiência para desenvolver trabalhos de planejamento, coordenação e acompanhamento de pesquisas em turismo. Ainda, a integração de instituições de ensino também foi salutar.

Quanto ao número de dados obtidos (Tabela 2), pode-se considerar que foi satisfatório diante de todas as adversidades. Quando concluída a convalidação dos dados com o trade, contabilizava-se 13.147 formulários preparados para o campo. Destes, 8.669 foram pesquisados com êxito, em 2.990 não houve êxito e 1.488 foram excluídos por diversos motivos. Entre os motivos estão formulários duplicados, estabelecimentos fechados, instalados em locais inseguros, que não quiseram participar, entre outros.

TABELA 2

Número de formulário convalidação (fase 2) e após campo (fase 3)

\begin{tabular}{lcccl}
\hline Subpolos & Fase $\mathbf{2}$ & Fase 3 & $\#$ & \% \\
\hline Agulhas Negras & 627 & 386 & 241 & 61 \\
Costa do Sol & 2.442 & 1.430 & 1.012 & 59 \\
Costa Verde & 3.523 & 2.724 & 799 & 77 \\
Metropolitana & 2.768 & 2.180 & 588 & 79 \\
Serra Verde Imperial & 2.094 & 1.202 & 892 & 58 \\
Vale do Café & 1.693 & 747 & 946 & 45 \\
\hline Total Média & $\mathbf{1 3 . 1 4 7}$ & 8.669 & $\mathbf{4 . 4 7 8}$ & $\mathbf{6 3 \%}$ \\
\hline
\end{tabular}

Fonte: Produto 8 - Relatório da Atividade de Campo da Oferta Turística, Rio de Janeiro, 2016.

Assim, a pesquisa de campo representou o preenchimento de, aproximadamente, $63 \%$ do total dos formulários preparados na pesquisa documental (fase de gabinete).

Destaca-se, que a dinâmica do mercado, no período de crise econômica do Estado do Rio de Janeiro, tem feito que haja rápidas mudanças na cadeia produtiva do turismo. Observou-se que vários equipamentos e serviços, levantados no campo, encerraram suas atividades e novos estabelecimentos foram abertos. Em 
tempos de Big Data, manter a pesquisa atualizada é uma questão fundamental para que ela tenha validade como instrumento de planejamento para políticas públicas e para os negócios.

Para o georreferenciamento dos dados, escolheu-se o software@Arcgis que foi alimentado com o levantamento das coordenadas geográficas capturadas durante a pesquisa documental utilizado o Google Maps e para a conferência no campo com GPS o software@NavFree, instalados nos tablets. Na escolha da compra dos tablets foi dada preferência para os que tivessem maior quantidade de pixel por polegada (PPI), pois as imagens seriam capturadas com estes equipamentos. As informações georreferenciadas possibilitaram a confecção de mapas para cada subpolo (Figura 3).

Os mapas georreferenciados foram adicionados nas nuvens e seu acesso se dá em um endereço eletrônico. Ao abri-los aparecem sobre o mapa pontos coloridos. Cada ponto representa um tipo de equipamento, serviço ou atrativo. Ao clicar sobre o ponto colorido, aparece os seguintes dados: nome do subpolo, município, $\mathrm{n}^{\circ}$ do formulário, categoria, tipo de estabelecimento, subtipo, nome oficial, nome fantasia, endereço, bairro, Código de Endereçamento Postal (CEP), latitude e longitude.

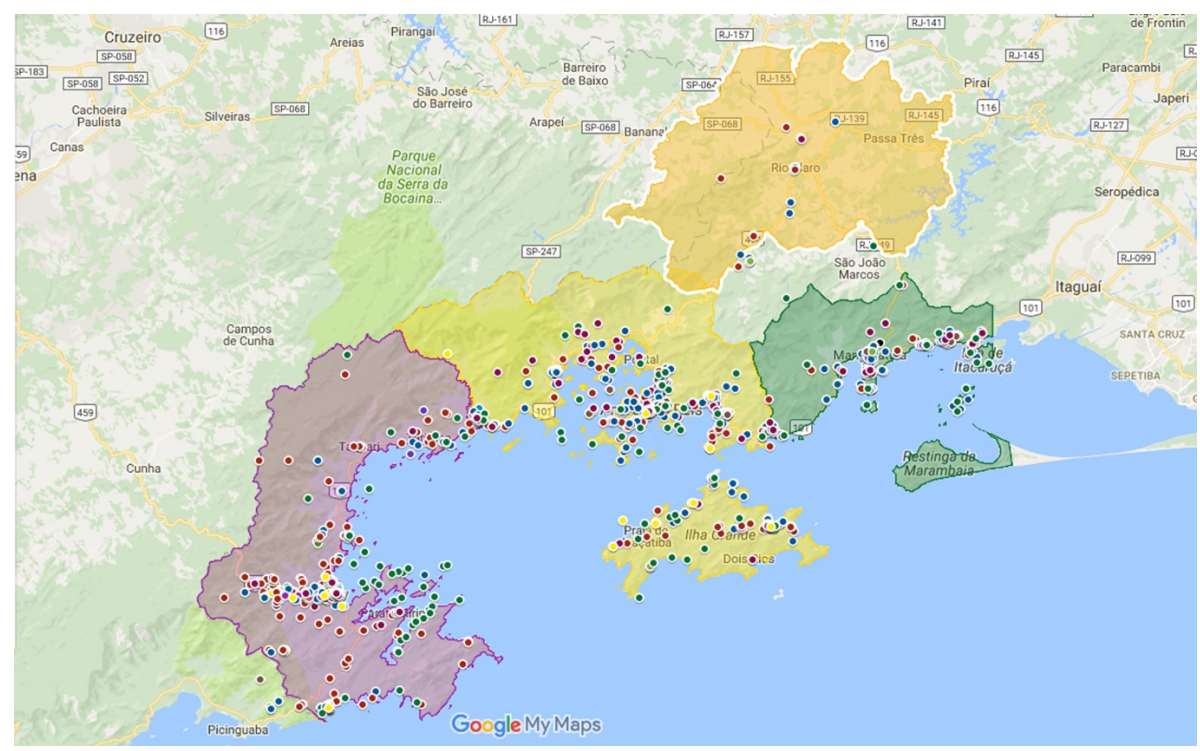

FIGURA 3

Mapa do Subpolo Costa Verde

Fonte: Produto 9: Mapas do Inventário da Oferta Turística, RJ 2016.



O Produto 10 tratou da Migração dos dados coletados para o sistema do inventário da oferta turística. Os dados contidos no Dropbox deveriam passar para o SIT desenvolvido pela SETUR RJ que conteria o Banco de Dados e os dados analisados, com mapas, fotos e conteúdos referentes aos inventários dos 23 
municípios. Por contrato, caso o sistema não existisse até a finalização do projeto IOT RJ executado pela UFF, o NUPTHS deveria entregar o banco de dados em planilhas executadas no software @MS Excel à SETUR RJ.

Infelizmente, não foi desenvolvido o SIT por parte da SETUR RJ por questões específicas relacionadas aos momentos econômicos que o Estado passou e, com isso, os dados foram concentrados em doze relatórios que totalizam mais de oitocentas páginas e as planilhas no software@MS Excel com 8.669 locais pesquisados e dentro de cada linha referente a cada local pesquisado há mais de mil colunas. Para a realização dos relatórios, os dados foram migrados usando o software@SPSS.Como é apenas um banco de dados em @MS Excel, cada vez que os dados precisarem ser manipulados pelos municípios ou pela SETUR será preciso fazer a migração com software específico.

Com a mineração dos dados para a confecção dos relatórios foi possível as consolidações de dados quantitativos sobre o inventário que permitiriam análise dos dados quanto as dimensões da oferta. Porém, como explicitado, ainda não há uma forma de visualizar o banco de dados. Assim, foi feito um acordo com a SETUR RJ, e o NUPTHS desenvolveu, com suas próprias custas, um caderno, por subpolo, com dados consolidados sobre o Inventário. Este teve 60 exemplares com impressão em papel e acesso em edição digital pelo site da SETUR RJ.

O Produto 11 referiu-se a um Caderno de Proposições. Neste documento, propôs-se a manutenção do inventário e o registro dos novos equipamentos, serviços turísticos e atrativos turísticos, bem como das potencialidades dos recursos turísticos ainda não reconhecidos para o turismo.

Uma das propostas, ali descrita, foi a criação do um Sistema de Gestão Integrada do Turismo (SIGTUR), que permite facilitar a manutenção do IOT-RJ e padronizar a inserção de dados no Estado do Rio de Janeiro, com vistas a apoiar os processos operacionais e decisórios da SETUR RJ.

A segunda proposta, foi a criação de uma Rede Colaborativa do IOT-RJ para atualização constante, acesso e gestão de informações, com ações, prazos e atores envolvidos para a continuidade do projeto. A proposição contém custos operacionais, nível de interdependência dos municípios, infraestrutura de recursos humanos necessários, chaves de acesso à informação, proposta para a criação de decreto-lei ou resolução que firme o comprometimento dos diversos atores envolvidos, e tudo o mais que é necessário à previsão de sustentabilidade do processo, bem como sua ampliação futura.

Sugere-se, ainda, a alteração do projeto de Lei que define os municípios de interesse turísticos do Estado do Rio de Janeiro, incluindo a exigência do IOT municipal e adequação da metodologia.

Com a ausência de um sistema integrado de informações estadual e o não funcionamento do federal, os dados seriam disponibilizados às prefeituras para inserção em seus sites, por meio de uma parceria com instituições que desenvolvem projeto de Destinos Inteligentes, que deve suprir as questões de comunicação com o uso de tecnologias de informação. Nesta negociação, além de um portal estadual, um aplicativo para o turismo do estado do Rio de Janeiro seria muito eficaz. Já existem aplicativos em alguns destinos que servem de material para estudos.

Isto posto, foi apresentada uma proposta no âmbito do projeto, de maneira que, caso existisse um sistema de informação com condições de ser alimentado, isso poderia ser realizado por meio dos Observatórios do Turismo e a criação de uma Rede Colaborativo Técnica entre as Instituições de Ensino Superior (IES) públicas e os municípios.

O Produto 12, Relatório Final, tratou da consolidação de todos os relatórios apresentando em um único documento com os resultados do IOT-RJ.

\section{Considerações Finais}

Ao analisar a execução do projeto IOT RJ, comunga-se com as considerações de Pinto quando afirma que o modelo de metodologia do inventário, estabelecido pelo Ministério do Turismo (MTur) e adotado na proposta do IOT-RJ, caracteriza-se por ser uma metodologia "fragmentada, reducionista, a- 
histórica, mecanicista, seguindo uma lógica positivista que não compreende o complexo fenômeno que é o Turismo" (2007, p. 135). Mesmo que Pinto se refira a análise da aplicação do modelo piloto nos municípios do Rio Grande do Sul, em que se utilizou a metodologia desenvolvida em 2006 do MTur, que foi revista em 2011, nesta nova experiência, percebe-se que estas características não foram suplantadas por serem estruturais.

Isso exige uma reflexão sobre não só a forma e conteúdo, mas objetivos e aplicações, da mesma, principalmente, no que tange à compreensão do turismo como um fenômeno social, político, cultural, ambiental e econômico que demanda maior participação dos residentes dos municípios no processo de seu planejamento e não apenas uma atividade econômica.

Assim, o inventário deve partir, em primeira instância, da percepção do turismo de seus moradores. $\mathrm{O}$ técnico deve trabalhar e tratar estes dados e apresentar uma devolutiva para ser analisada em conjunto com os moradores e construir um diagnóstico que sirva de orientador para o planejamento. A necessidade de uma construção que saia da própria municipalidade é fundamental para que ela seja significativa e decidida por ela, como o próprio PRODETUR já destacava, nos anos 2000, com a exigência da elaboração do PDITS.

Não cabe aqui as diversas críticas quanto a abrangência destas participações dos residentes. Muitos apontam que a representatividade não é significativa e apenas a opinião e interesse de alguns são acatados. O que não deixa de ser verdade, em muitos casos, mas há novos instrumentos de co-criação e de acesso a meios de comunicação que podem envolver mais pessoas e fazer esta ação de inventariação, um ato constante e participativo. Pois, o que se tem percebido, incluindo a divulgação dos resultados do IOT RJ, por parte da mídia, é a ideia do inventário como um acontecimento efêmero e não uma atividade que necessita de constante atualização, seguindo a dinâmica das nossas sociedades.

Os inventários devem alimentar um banco de dados, e, para que este tenha um potencial estratégico, é preciso que os dados sejam vasculhados e definidos com padrões válidos, úteis e compreensíveis. Tal tarefa não é apenas identificá-lo, mas requer o uso de técnicas de tratamento de dados para que se tenha estes padrões. Também, outras formas de aplicação de tecnologias móveis, realidade aumentada, sistema de posicionamento global são imprescindíveis para um inventário contemporâneo.

Quando o projeto foi criado, era objetivo da SETUR RJ/UFF (Rio de Janeiro, 2016) sanar as lacunas das experiências anteriores, sobre a inventariação do Estado do Rio de Janeiro com inventários pontuais e descontínuos, além de não se ter padronização para levantamento dos dados e acesso democraticamente, aos mesmos, política de monitoramento e atualização.

Como descrito anteriormente, a padronização até poderia ocorrer, pois usou-se o modelo do INVTur do MTur, mas este modelo apresenta problemas e não possui mais acompanhamento federal. Portanto, é necessário o estudo de uma metodologia inserida nas novas necessidades do turismo, das organizações sociais contemporâneas e na disponibilidade das inovações tecnologias.

Os demais itens, como continuidade e atualização constante, acesso aos dados e monitoramento, dependem, principalmente, de três fatores no uso da tecnologia: softwares e equipamentos para as pesquisas documental e de campo, conexão com alta velocidade e com abrangência total nos municípios e um SIT.

No caso do IOT RJ, o que era para ser um diferencial na pesquisa, uso da tecnologia, acabou sendo um obstáculo para os pesquisadores e para o projeto. A escolha equivocada de adaptar um software e não desenhar um novo, fez com que ao término do projeto não exista um software para dar continuidade ao mesmo. Esta exigência não era contratual, mas poderia fazer a diferença na continuidade, com a atualização. Além, evidentemente, das dificuldades observadas, no gabinete e no campo, por causa dos problemas causados pelo uso deste software.

Mas, por outro lado, fazer a pesquisa toda por meio digital trouxe muitos benefícios de sustentabilidade, por não usar formulários em papel, mais rapidez na consolidação das informações, a possibilidade de migrar informações, coletar dados de georreferenciamento com o GPS e de imagem diretamente no tablet. 
Verificou-se, também, que um dos problemas nos destinos inventariados estava na conexão de internet em muitos atrativos e equipamentos turísticos e em outros, ela existia, mas era de baixa velocidade para transmissão de dados. Com isso, notou-se que nos destinos inventariados é imperativo o investimento em tecnologia de comunicação, levando à discussão sobre a maturidade tecnológica e o turismo no interior do Estado.

Outra questão fundamental era a democratização dos dados. A ausência de um SIT no estado do Rio de Janeiro, voltado ao turismo, fez com que o principal objetivo do projeto não se concretizasse. Sem a divulgação dos quase nove mil dados de formulários, que não foram migrados para um banco de dados, fica muito difícil dar continuidade, monitorar e atualizar os dados. Os cadernos confeccionados pela UFF apenas publicaram resumos dos dados e não conseguiram suprir com todas informações que o planejamento exige.

Quanto a equipe, foi um fator muito positivo a inclusão de professores, estudantes e especialistas no projeto, tanto para aprendizagem pessoal quanto coletiva, além da integração de IES. Para realizar um inventário é preciso seguir um planejamento detalhado, ter recursos financeiros e materiais suficientes, equipe engajada, treinada e estimulada. O inventário é um trabalho árduo, em equipe, e, de preferência, deve ser realizado dentro de algumas condições específicas, como ocorrer na baixa temporada para não atrapalhar o trabalho dos depoentes nas entrevistas, procurar épocas de estiagem para que as pesquisas ao ar livre não sejam prejudicadas e as estradas de terra permitam o acesso.

Além disso, trabalhar em vários municípios exige um planejamento muito bem elaborado, quanto as visitações, para que as pesquisas previstas possam ser realizadas dentro do tempo e com o número de pesquisadores estipulados no projeto.

Cabe ainda destacar, nestas considerações finais, que o PRODETUR RJ, maior linha de investimentos posta em curso para fomentar o turismo, na história do estado ${ }^{[6]}$, ao qual o IOT RJ fez parte, foi uma grande oportunidade que o estado teve de alinhar planejamento e desenvolvimento do setor de turismo em todo o estado (Lima, 2014). No entanto, o período de sua execução, que inicialmente era 2015, mas que passou por aditamentos de mais de dois anos, foi um momento bastante conturbado para gestão pública no estado, que passava por denúncias e descobertas de esquemas de corrupção, retenção de recursos, e outros, que desviaram a atenção dos responsáveis e, provavelmente, derivaram em prejuízos nos seus resultados.

Um prejuízo já se evidenciou no não desenvolvimento de um SIT, como era previsto, que serviria de base para sistematização dados gerados pelo IOT RJ. Nesse sentido, há que se esperar o tempo para poder se avaliar demais perdas que a situação descrita acarretou ao seu resultado esperado com o PRODETUR RJ e os avanços por ele proporcionados no alinhamento planejamento e desenvolvimento do setor no estado.

Ademais, considerou-se, pelos autores, que o projeto IOT RJ obteve muitos bons resultados e, também, dificuldades. Há vários dados que podem auxiliar na leitura do turismo no Rio de Janeiro e, mesmo com um pouco de defasagem, pode-se ter a continuidade do processo. Portanto, é preciso se ter vontade política que envolva a todos: organismo público, residentes, trade e IES para redesenhar um novo cenário.

\section{REFERÊNCIAS}

Almeida, M. (2009). Matriz de avaliação do potencial turístico de localidades receptoras. Revista Turismo em Análise. São Paulo, 20 (3), 541-561. Disponível em http://www.revistas.usp.br/rta/article/view/14200/16018 . Acessado em 20 de novembro de 2018.

Almeida, R.\& Moura, A. (2009). A atuação do trade no inventário turístico de João Pessoa a partir da ótica dos alunos pesquisadores. VI Seminário ANPTUR. São Paulo. Disponível em https://www.anptur.org.br/anais/anais/file s/6/162.pdf. Acessado em 15 de dezembro de 2018.

Alves, F. G.; Costa, H. S.\& Perinotto, A. R. C. (2017). Instagram como ferramenta para fidelização de clientes: Fotografia, Redes Sociais e Turismo. Marketing \& Tourism Review. Belo Horizonte, 2 (2), 1-21. 
Bahia. UESC.(2011). Inventário turístico e indicadores de sustentabilidade. Disponível em: https://invturcostad ocacau.wordpress.com/2011/10/24/inovacao-no-inventario-turistico-trara-mais-beneficios-aos-municipios/ . Acesso em 18 jan. 2018.

Beni, M. C. (2018). Análise estrutural do turismo. Ed. Revisada e ampliada. São Paulo: Senac.

Biz, A. A.; Massukado-Nakatami, M. S.\& Pavan, C. S. (2013). Análise da Gestão da Informação na Secretaria de Estado do Turismo do Paraná SETU/PR. Revista Turismo em Análise, 24, 278-297.

Brasil. (1979). Empresa Brasileira de Turismo. Identificação do Espaço Turístico Nacional. Rio de Janeiro: EMBRATUR.

Brasil. (1999). Empresa Brasileira de Turismo. Diretrizes do programa nacional de municipalização do turismo. Brasília, EMBRATUR.

Brasil. (2006). Ministério do Turismo. Secretaria Nacional de Políticas de Turismo, Departamento de Estruturação, Articulação e Ordenamento Turístico. Projeto Inventário da Oferta Turística. Brasília: Ministério do Turismo.

Brasil. (2007). Programa de Regionalização do Turismo - Roteiros do Brasil: Introdução à Regionalização do Turismo. Brasília: Ministério do Turismo.

Brasil. (2013). Plano Nacional de Turismo 2013-2016. O turismo fazendo muito mais pelo Brasil. Brasília: Ministério do Turismo.

Bursztyn, I. (2003). A influência do ideário neoliberal na formulação de políticas públicas de turismo no Brasil. Caderno Virtual de Turismo. Rio de Janeiro, 3 (4), 6-12.

Costa, J.; Rita, P.\& Águas, P. (2001). Tendências internacionais em turismo. Lisboa: Lidel Edições Técnicas.

Ignarra, L.R. (2013). Fundamentos do Turismo. $3^{\circ}$ ed. Rio de Janeiro: Senac.

Lage, B \&Milone, (Org). (2001). Turismo: teoria e prática. São Paulo: Atlas.

Laudon, K; Laudon, J. Management information systems. New Jersey: [s. n.], 2002.

Lima, V.M.S. (2014). Gestão Pública do Turismo no Estado do Rio de Janeiro: Dilemas e Perspectivas. Revista Eletrônica Sistemas \& Gestão. 9 (3), 356-368

Martins, P. (2006). Administração de materiais e recursos patrimoniais. 2 ed. São Paulo: Saraiva.

Moesch, M \& Pinto, D. (2006). Inventariação turística: por um modelo de superação metodológica. IV SemiTUR Seminário de Pesquisa em Turismo do MERCOSUL. Caxias do Sul: UCS, Disponível em: https://www.ucs.br /ucs/tplSemMenus/eventos/seminarios_semintur/semin_tur_4/arquivos_4_seminario/GT14-14.pdf. Acesso em: 11 jan. 2018.

Moura, A.; Gondim, C; Pinheiro, L.\& Simões, V. (2009). Metodologia da Pesquisa de Campo no Projeto Inventário da Oferta Turística do Município de João Pessoa - PB: Caminhos e Descaminhos. In: VI Seminário da ANPTUR. 2009, São Paulo. São Paulo: Aleph. $6^{\circ}$.

Paiva, M.G. (2010). Análise do Programa de Desenvolvimento do Turismo do Nordeste (Prodetur/NE) na perspectiva do planejamento estratégico. Revista de Administração Pública. Rio de Janeiro, 44 (2), 197-213, mar/abril.

Paiva, M.G. (1995). Sociologia do turismo. 7 ed. Campinas: Papirus.

Perantoni, A; Silva, L \& Nagabe, F. (2012). Inventário turístico: experiências acadêmicas com metodologias e práticas no planejamento do Turismo no Pontal Paulista/SP. Disponível em. https://periodicos.ufff.br/index.php/abet /article/view/3033 Acesso em 20 de janeiro de 2018.

Pinto, D. (2007). Os desafios metodológicos para uma abordagem científica do Turismo: O inventário turístico. (Dissertação). Universidade Caxias do Sul. Caxias do Sul.

Rio de Janeiro. (2018). Plano de Desenvolvimento Integrado do Turismo Sustentável. PRODETUR. Disponível em http://www.prodetur.rj.gov.br/planodesenvolvimento.asp. Acesso em 20 jan. 2018.

Rio De Janeiro. (2016). PRODUTO 1 ao 12. Projeto de Inventariação dos Destinos Turísticos do Rio de Janeiro. Rio de Janeiro: SETUR/UFF.

Sancho, A. (2001). Introdução ao Turismo. Tradução de Dolores Martin Rodriguez Corner. São Paulo: Roca. 
Trentin, F.\& Fratucci, A. C. (2011). Política Nacional de Turismo no Brasil: da municipalização à regionalização. International Conference On Tourism \& Management Studies, Algarve, 1, 839-848.

Wahab, S. (1997). Introdução à Administração do Turismo. Rio de Janeiro: Pioneira.

\section{Notas}

[1] Para o Produto 4, bem como para o Produto 7, o método e as técnicas que foram adotados foram as contidas nos documentos o INVTur do Mtur (2011). Por esse motivo, apresentamos o Produto 5 e 6 e depois retornamos ao Produto 4 que é discutido juntamente com o Produto 7.

[2] Disponível em "http:www.visitesaopedrodaaldeiada.br". Acesso em 20 mar. 2015.

[3] Mês de referência: fevereiro de 2015.

[4] Para a produção dos Cadernos do IOT-RJ estes dados foram revistos.

[5] Os recursos para o pagamento dos pesquisadores teriam origem na entrega dos produtos e estes somente puderam começar a ser entregues a partir de outubro de 2015 , visto que a assinatura do contrato só aconteceu em setembro de 2015. O quadro foi agravado, visto que uma instituição pública tem problemas de recebimento de pagamentos após outubro pelo fechamento do ano fiscal e até aprovação do orçamento no ano seguinte, ficando o pagamento dos produtos suspensos de novembro até março. Tanto para a pesquisa de campo quanto para o pagamento dos pesquisadores da fase documental, só houve recursos após março de 2016.

Destaca-se que durante a pesquisa ocorreu a maior crise econômica, deste século, no Estado do Rio de Janeiro. A queda no preço do barril de petróleo e, consequentemente, a diminuição na arrecadação de royalties pelo estado, o escândalo de corrupção da Petrobras, a diminuição na arrecadação de ICMS, também devido à crise econômica, os gastos com a organização dos Jogos Olímpicos e da Copa do Mundo e, ainda, falhas na administração das contas públicas, foram algumas das causas identificadas.

Uma instituição federal de ensino não tem como desenvolver um projeto sem receber o pagamento pelos produtos entregues. Não é uma instituição privada, com fluxo de caixa para pagamentos inesperados. O setor público trabalha baseado em orçamentos aprovados pela universidade e pelo Ministério da Educação (MEC). Além disso, a FTH é uma instituição recente e não conta com muitos recursos para sua gestão, não possui ativos para cobrir custos inesperados de projetos. Quando se decidiu participar da licitação, em 2013, o Estado não estava em crise e se esperava que os produtos fossem pagos nas datas planejadas no plano de trabalho, o que evitaria uma série de dissabores.

[6] Recursos da ordem de US\$ 187 milhões (Lima, 2014, p.361) 